\title{
Performance and nonperformance learning under partial reinforcement
}

\author{
A. J. MARCATTILIO \\ Butler University, Indianapolis, Indiana 46208
}

\begin{abstract}
One group of rats was trained to learn a maze in the traditional manner, while a second group was hand-carried through the maze (during pretraining) for an equal number of trials. Throughout the experiment, reinforcement was available on every third trial for all subjects. When subjects in the second group were allowed to traverse the maze in the usual manner during testing, they made fewer errors and exhibited lower running time as compared to the traditionally trained subjects. Furthermore, both groups exhibited fewer errors and lower running times on trials immediately following reinforcement than on reinforced and prereinforced trials. The results suggested that instrumental performance is not a prerequisite for learning.
\end{abstract}

While a number of investigators have attempted to demonstrate learning without performance, their primary objective of eliminating instrumental responses in the course of training has not been adequately achieved (Dodwell \& Bessant, 1960; Gleitman, 1955; McNamara, Long, \& Wike, 1956). The design typically employed in examining the effects of nonperformance in learning has included the use of a control group of rats trained to learn a maze situation in the traditional manner to a set criterion. The experimental animals are then pretrained for the same number of trials the control group needed to reach criterion in a manner such that responding is not necessary on the part of experimental subjects. This has been done by placing the experimental subject in a wooden or Plexiglas "car" which is then transported through a maze. All experimental conditions are the same for both control and experimental subjects, except that the experimental group need not perform to turn a corner, run an alley, or secure reinforcement (except for consummatory behaviors). Although these studies indicate that instrumental performance is not necessary for learning to take place, a methodological problem is inherent in that the transporting devices may have been large enough to allow for the occurrence of instrumental responding. For example, Dodwell and Bessant (1960), using a complex maze and the swimming response, presented pictures of rats leaning out of the trolley and "bending with the turn." This type of behavior could allow for the buildup of $S-R$ connections, perhaps in the form of $\mathrm{r}_{\mathrm{gS}-\mathrm{Sgs}}$, which could be used as an explanatory tool for

The author wishes to thank Dr. Byron A. Campbell for providing the animals and laboratory facilities at Princeton University, and Dr. Burrton G. Woodruff for his aid with the statistical analyses. Address reprint requests to the author, Department of Psychology, Colorado State University, Fort Collins, Colorado 80523. This paper is sponsored by William N. Boyer, who takes full editorial respons bility for its contents. the behavior exhibited by the experimental animals during testing. Indeed, Trapold and Doren (1966) have reported that rats that had to run a small distance to secure reinforcement showed greater resistance to extinction than rats placed directly over the food dish, thus demonstrating that even minimal amounts of responding, as compared to no responding, have differential effects on learning, or as in this case, extinction. As a result, interpretation of the data is difficult, in that the mechanisms of learning, be they performance or some other mechanisms, are not readily identified.

One way to prevent possible instrumental responding during pretraining (without traumatizing the subject) is to hand-carry the subject through the maze. Menzel (1973) has demonstrated this as a viable alternative with chimpanzees as subjects. Since rats become quite docile and show no indication of adverse emotions when handled and gentled a great deal, one could easily hold the animal firmly in hand, transport it through the maze, and at the same time prevent the occurrence of any overt responding. It was this methodological consideration that was the focal concern of the present investigation. It was also of interest to equate handling and carrying experience across all subjects, since there seems to have been a neglect for this control in the Menzel investigation. Finally, the present study also attempted to determine if nonperformance learning could take place while subjects were exposed to a partial reinforcement schedule.

\section{METHOD}

\section{Subjects}

The subjects were 20 naive male adult rats of the Sprague-Dawley strain, with a mean weight of $338 \mathrm{~g}$ at the start of the experiment. The subjects were divided equally between two groups, Group P (performance in training) and Group $\mathbf{N}$ (nonperformance in pretraining), and housed in community cages respective of their group assignments. 


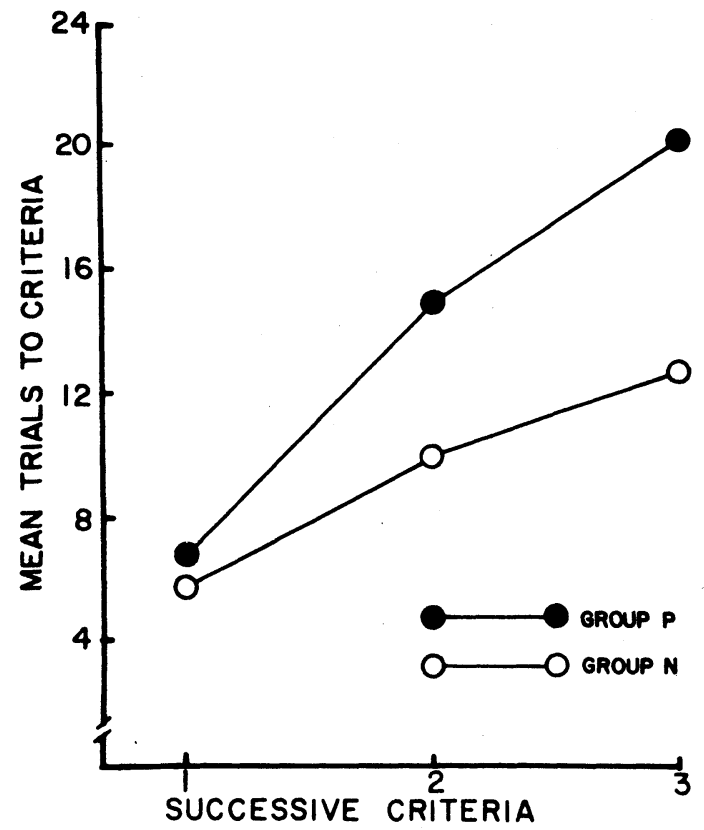

Figure 1. Mean trials to successive criteria $(1,2$, and 3 errorless trials) for both groups. See text for explanation of computational procedures.

\begin{abstract}
Apparatus
The apparatus was a five-unit multiple-T-maze constructed of Plexiglas. The alleys were 15.24 to $30.48 \mathrm{~cm}$ in length and $25.40 \mathrm{~cm}$ in width, with walls $15.24 \mathrm{~cm}$ high. The startbox was $15.24 \mathrm{x}$ $25.40 \mathrm{~cm}$, and the goalbox was $35.56 \times 35.56 \mathrm{~cm}$. The base of the maze (which was $60.96 \mathrm{~cm}$ above the floor of the experimental room) was painted flat black and cut in the same pattern as the walls were constructed.

The experimental room was held constant in extra-maze cues. These cues consisted of an open doorway along Alley 1, a silver chain hanging at Choice Point 3 , a silver box attached to the wall opposite Choice Point 5 , a high-intensity desk lamp illuminating the goalbox, bedding in the goalbox, strips of black elecrician's tape placed at the choice points of the maze, and the experimenter standing at the blind end of Alley 3.
\end{abstract}

\section{Procedure}

Subjects in Group $P$ were adapted to a 23 -h food-deprivation schedule for 6 days prior to training and given 5 min of free exploration and goalbox habituation in the maze per day for 3 days prior to training. Group $P$ subjects were then trained in the customary manner. A subject was placed in the startbox for $10 \mathrm{sec}$, at which time the hatch was opened and the animal was allowed to find its way to the goalbox. A partial schedule of reinforcement was employed with reinforcement (access to three standard Purina Lab Chow peilets) given on Triais $1,4,7, \ldots, n$. At the end of each trial, the subject was kept in the goalbox for $1 \mathrm{~min}$, whether or not reinforcement was given. Intertrial intervals were $10 \mathrm{sec}$ long. Group $\mathbf{P}$ subjects were trained to a criterion of three successive errorless trials. There were 19 trials on Day 1, and if any subject did not reach criterion at this time, it was run to criterion on Day 2.

After adaptation to the deprivation schedule and the apparatus in the same fashion as Group P subjects, Group N subjects were trained by hand-carrying them through the correct maze pathway for the mean number of trials (20), and at approximately the mean running speed per subject per trial $(22 \mathrm{sec})$ as established by Group P. Though the subject was held firmly in the experimenter's hands and could not move, vision was not impaired and the animal could see only what was in front of it. Upon reaching the goalbox, each subject was placed directly over the food cup and left in the goalbox for $1 \mathrm{~min}$, again whether or not reinforcement was delivered. Two hours after each subject's training session, each subject was tested in the same manner that Group P subjects were trained.

All animals were given equal preexperimental handling experience, that is, $20 \mathrm{~min}$ a day for 10 days prior to training plus normal handling during the experimental session. Since Group $\mathbf{N}$ subjects would be carried through the maze, Group $\mathbf{P}$ rats were carried through "space" in a random fashion on the moring of the first training session for approximately the same total amount of time that Group $\mathrm{N}$ animals would be carried through the maze. Pilot data indicated this approximate handling/carrying time.

\section{RESULTS}

Three measures of behavior were employed for purposes of analysis: (a) trials to criterion, (b) running time, and (c) errors (defined as half the animal's body traversing the farthest wall of a choice point). T-test analysis computed on the first of these measures revealed that, on the average, Group $N$ subjects took fewer trials to criterion than Group $P$ subjects $[\mathrm{t}(18)=2.876, \mathrm{p}<.02] . \quad$ Figure 1 graphically depicts the mean number of trials to successive criteria for both groups. Specifically, a group mean was calculated from the total number of trials individual subjects in each group needed to complete 1, 2 (successive), and 3 (successive) errorless runs through the maze (see Underwood, 1966, pp. 453-455).

Under the schedule of reinforcement used, there were three types of trials, (a) reinforced trials (R), (b) prereinforced trials $(\mathrm{R}-1)$, and (c) postreinforcement trials $(R+1)$. In order to analyze the differences in running time between the groups in terms of these trial types, a 2 (groups) by 3 (trial types) analysis of variance with repeated measures on the last factor was conducted on these data. The results indicated that Group N subjects had lower running times than Group $P$ subjects $[F(1,18)=9.33$, $\mathrm{p}<.01]$. There was also a significant trial type effect $[F(2,36)=8.03, p<.005]$, but no reliable Groups by Trial Type interaction $(F<1)$ effect. Because it was of interest to determine the nature of the differences in these trial types, orthogonal comparisons were applied to the trials data, and the findings indicated that across subjects in both groups there was no difference in running times on $R$ and $R-1$ trial types $[F(1,36)=p>.10]$, but that running time on both $R[F(1,36)=15.13, p<.001]$ and $R-1$ $[F(1,36)=7.72, p<.01]$ trial types were significantly higher than running time on $R+1$ type trials. By the same token, a comparable 2 by 3 analysis of variance on errors showed that Group $\mathbf{N}$ animals made fewer errors than Group $P$ animals $[F(1,18)=11.26$, $\mathrm{p}<.005]$. In addition, a significant trial type effect was evident $[F(2,36)=5.42, p<.01]$, but there was no significant Groups by Trial Type interaction $(F<1)$. Orthogonal comparisons again showed the same results. That is, across all subjects, there was no 
difference in the number of errors on $\mathrm{R}-1$ and $\mathrm{R}$ type trials $(F<1)$. However, fewer errors were made on $R+1$ type trials as compared to $R$ and $R-1$ type trials $[F(1,36)=9.31, p<.005$, and $F(1,36)=6.75$, $\mathrm{p}<.025$, respectively].

\section{DISCUSSION}

The present data are in agreement with those of Dodwell and Bessant (1960, Gleitman (1955), McNamara et al. (1956), and Menzel (1973) in suggesting that performance is not necessary for learning to take place. Moreover, possible flaws in the procedural techniques inherent in past investigations could be eliminated with the use of the present methodology. It should be noted that although handling facilitates learning (Bernstein, 1957; Christie, 1951; Karn \& Porter, 1946), any biasing implicit in the present investigation as a result of this variable is minimal, since all animals were handled and carried through space for approximately equal amounts of time. By the same token, overt responding on the part of Group $\mathrm{N}$ subjects during training was nonexistent, since they remained passively in the experimenter's hand while being transported through the maze. This procedure might be utilized in experiments examining different types of discrimination (e.g. brightness and form) tasks, positive and negative reinforcement, as well as other variables (such as physiological substrates of learning).

A secondary finding of interest in the present study was that both groups exhibited better performance (faster running speeds and fewer errors) on $R+1$ type trials. This might indicate some type of carry-over effect of reinforcement from the preceding trial to $R+1$ type trials which was not evident on the $R$ and $R-1$ type trials. Research might be directed at examining such findings in different reinforcement schedules.

A number of learning mechanisms can be used to explain the present data. For example, Bolles (1972), in a recent systematization of the S-S (Tolman, 1932) position, denies the necessity of the response in order for learning to take place. Though he admits that behavioral correlates of particular cognitive processes exist, he does suggest that the behavior is not a prerequisite for learning. On the other hand, though overt responding on the part of the experimental subjects did not take place, certain mechanisms within the $S-R$ framework could be employed to explain the present findings. More specifically, one could suggest that even though overt responding did not take place, such responses as eye movement, increased respiration, and any one of a number of fractional anticipatory responses $\left(r_{g} s\right)$ did. Thus, learning may have taken place via the formation of the $\mathbf{r}^{-s} \mathbf{g}$ mechanism.

Though any number of mechanisms might be used to explain the present data, it seems that performance is not a necessary prerequisite for learning. Furthermore, this type of learning can take place under partial reinforcement with certain performance characteristics associated with particular aspects of the schedule employed.

\section{REFERENCES}

BERNSTEIN, L. The effects of variations in handling upon learning and retention. Journal of Comparative and Physiological Psychology, 1957, 50, 162-167.

Bolles, R. C. Reinforcement, expectancy, and learning. Psychological Review, 1972, 79, 394-409.

Christie, R. Experimental naivete and experiential naivete. Psychological Bulletin, 1951, 48, 327-339.

DodWEll, B. C., \& BessaNt, D. W. Learning without swimming in a water maze. Journal of Comparative and Physiological Psychology, 1960, 53, 422-425.

Gleitman, H. Place learning without prior performance. Journal of Comparative and Physiological Psychology, 1955, 48, 77-79.

KARN, H. W., \& Porter, J. M. The effects of certain pre-training procedures upon maze performance and their significance for the concept of latent learning. Journal of Experimental Psychology, 1946, 36, 461-469.

McNamara, H., Long, J., \& Wike, E. Learning without response under two conditions of external cues. Journal of Comparative and Physiological Psychology, 1956, 49, 477-480.

Menzel, E. W. Chimpanzee spatial memory organization. Science, 1973, 182, 943-945.

Trapold, M. A., \& Doren, D. G. Effect of non-contingent partial reinforcement on the resistance to extinction of runway response. Journal of Experimental Psychology, 1966, 71, 429-431.

Tolman, E. C. Purposive behavior in animals and men. New York: Appleton-Century-Crofts, 1932.

UNDERWOOD, B. J. Experimental psychology. New York: Appleton-Century-Crofts, 1966.

(Received for publication July 31, 1975.) 